\title{
Tipik ve Atipik Antipsikotik İlaç Kullanımına Bağlı EEG Anormallikleri
}

\section{EEG Abnormalities Associated with the Use of Typical and Atypical Antipsychotics}

\begin{abstract}
Özet
Amaç: Tipik antipsikotikler ve klozapin EEG anormalliklerine ve epileptik nöbetlere neden olabilir. Yeni kuşak antipsikotiklerin EEG üzerindeki etkileri çok fazla bilinmemektedir. Yapılan bu çalışmada klozapin, ketiapin, risperidon ve olanzapin gibi atipik antipsikotikler, amisülpirid, aripiprazol, paliperidon gibi yeni diğer atipik antipsikotikler ve klorpromazin, haloperidol, zuklopentiksol, pimozid gibi tipik antipsikotiklerin EEG anormallikleri üzerine etkileri araştırılmıştır.

Gereç ve Yöntemler. Şizofreni veya şizoaffektif bozukluk tanılı 102 hasta prospektif olarak değerlendirilerek EEG'leri çekildi. Bunların 82'si atipik [klozapin (n:16), risperidon (n:20), ketiapin (n:10), olanzapin (n:14), diğer yeni atipik antipsikotikler (n:10)] ve tipik [haloperidol (n:5), klorpromazin (n:2), zuklopentiksol (n:3), pimozid (n:2)] antipsikotik kullanıyordu, 20'si ise ilaç kullanmıyordu. Bu üç alt grup; cinsiyet ve yaş uyumlu sağlıklı kontrol grubunun (n=29) EEG'leri ile karşılaştıııldı.

Bulgular: Gruplar arasında demografık özellikler bakımından istatiksel olarak anlamlı fark saptanmadı. Hem ilaç kullanmayan hastaların hem de sağlıklı kontrollerin EEG'leri normaldi. Klozapin kullanan hastaların \% 31,3'ünde ( $p<0,05)$, ketiapin kullananların da \%10'unda ( $p>0,05)$ epileptik aktivite gözlendi. Epileptik aktivite dışındaki EEG anormallikleri tipik antipsikotik kullananların $\% 58,3^{\prime}$ ünde $(p<0,01)$, risperidon kullananlarında \%35'inde $(p<0,01)$ saptandı. EEG ketiapin ve yeni atipik antipsikotik kullananların \%80'inde normalken, tipik antipsikotik kullananların \%33,3'ünde normaldi $(p=0,012)$.
\end{abstract}

Tartışma ve Sonuç: Burada klozapinin en epileptojen antipsikotik olduğunu ve tipik antipsikotiklerin EEG'yi en fazla bozduğunu bulduk. Ancak klozapin tedavisi alan psikotik hastalarda EEG bir gerekliliktir. Epilepsinin eklendiği psikotik hastalara yeni atipik antipsikotikler verilebilir, çünkü EEG üzerine en az istenmeyen etkiler bu ilaçlarla gözlenmiştir. Buna ilaveten antipsikotik ilaçlar ve epilepsi eşiği arasındaki kompleks ilişkileri açığa çıkarmak için daha fazla bilimsel araştırmaya ihtiyaç olduğunu da vurgulanmamız lazımdır.

Anahtar Kelimeler. elektroensefalografi; tipik antipsikotikler; atipik antipsikotikler; epileptik aktivite

\section{Abstract}

Aim: Typical antipsychotics and clozapine could cause EEG abnormalities and risk of epileptic seizures. Little is known about the effects of newer antipsychotics on EEG. The present study therefore examined the risk of EEG abnormalities associated with the use of atypical antipsychotics [clozapine, quetiapine, risperidone, olanzapine and new atypical antipsychotics (amisulpride, aripiprazole, paliperidone)] and of the typical antipsychotics (chlorpromazine, haloperidol, zuclopenthixol, pimozide).

Materials and Methods: EEG patterns were prospectively investigated in 102 patients with schizophrenia or schizoaffective disorders. While 82 out of the 102 patients were under atypical [clozapine $(n=16)$, risperidone $(n=20)$, quetiapine $(n=10)$, olanzapine $(n=14)$, and new atypical antipsychotics $(n=10)$ ] and typical [haloperidol $(n=5)$, chlorpromazine $(n=2)$, zuclopenthixol $(n=3)$, pimozide $(n=2)]$ antipsychotic treatment, 20 of them were not under any treatment. These three groups were compared with a sex- and aged- matched control group of healthy volunteers $(n=29)$.
Süreyya Ekem', Nida Fatma Taşcılar², Esra Acıman Demirel $^{3}$, Banu Özen Barut ${ }^{4}$, Handan Ankaralı ${ }^{5}$, H. Tuğrul Atasoy ${ }^{3}$

Zonguldak Atatürk Devlet Hastanesi Nöroloji, Zonguldak

2 Medipol Üniversitesi Hastanesi Nöroloji AD, İstanbul

${ }^{3}$ Bülent Ecevit Üniversitesi Nöroloji AD, Zonguldak

${ }^{4}$ Dr. Lütfı Kırdar Kartal Eğitim ve Araştırma Hastanesi Nöroloji, İstanbul 5 Düzce Üniversitesi Tıp Fakültesi, Biyoistatistik ve Tıbbi Bilişim AD, Düzce.

Geliş Tarihi /Received : 30.03.2016 Kabul Tarihi /Accepted: 06.04.2016

Sorumlu Yazar/Corresponding Author Dr. Esra Acıman Demirel Birlik Mah. Şifa Sokak, 39 Merkez/Zonguldak

E-mail: esraaciman@yahoo.com 
Results: No statistically significant difference regarding demographic characteristics was found between the groups. Both the patients who were not on any medication and the healthy volunteers had normal EEG's. Epileptic activity was observed in $31.3 \%$ of the patients under clozapine treatment $(p<0.05)$ and in $10 \%$ of the patients under quetiapine treatment $(p>0.05)$. EEG abnormalities other than epileptic activity were observed in $58.3 \%$ of the patients under typical antipsychotics $(p<0.01)$ and $35 \%$ of the patients under risperidone treatment $(p<0.01)$. EEG was normal in $78-80 \%$ of the patients using quetiapine and new atypical antipsychotics, compared to $33.3 \%$ of the patients under typical antipsychotic treatment $(p=0.012)$.

Discussion and Conclusion: Herein, we found that clozapine was the most epileptogenic antipsychotic and that typical antipsychotics were making the worse EEG changes. Nevertheless, in the psychotic patients under clozapine treatment EEG is a must. Psychotic patients with consequential epilepsy could be given new atypical antipsychotics because it has the least unwanted effects on EEG. Moreover, it should also be emphasized that there is a need for further scientific research to clarify all aspects characterizing the complex link between seizure threshold and psychotropic drugs.

Key Words: electroencephalography; typical antipsychotics; atypical antipsychotics; epileptic activity

\section{GíRiş}

Farklı idiyopatik psikiyatrik hastalığı olan kişilerde EEG anormallikleri görülebilmektedir (1). Bu anormalliklerin öncelikle psikiyatrik hastalığa mı bağlı olduğu yoksa primer beyin disfonksiyonundan mı kaynaklandığı, ya da kullanılan medikal tedavilerle mi ilişkili olduğu netlik kazanmamıştır. Tipik antipsikotik (TAP) ilaç kullananlarla yapılan çalışmalarda EEG'de zemin aktivitesinde yaygın yavaşlama, yavaş dalga aktivitesi, alfa ritminde artış, klinik bulgunun eşlik etmediği paroksismal bozukluk ya da epileptiform anomaliler gözlemlenmektedir $(2,3)$. Atipik antipsikotik (AAP) ilaç kullanan psikotik hastalarla yapılan çalışmalarda hastaların \%30'unda temporal lobda EEG anormalliği (4), \% 2,6'sında ise epileptiform aktivite bildirilmiştir (5). Bir AAP olan klozapinin EEG aktivitesi üzerine belirgin etkileri vardır ve doz bağımlı olarak çeşitli epileptik nöbetlere neden olduğu bilinmektedir $(6,7)$. Her ne kadar AAP'lerde reseptör seçiciliğinin olması, epileptik aktivite ve EEG anormallikleri gibi yan etkilerin TAP'lere kıyasla az olabileceğini düşündürtse de AAP kullanan olgularda EEG bulguları netlik kazanmamıştır ve bu konuda yapılan çalışma sayısı azdır (8). Çalışmamızın amacı TAP ve AAP'lerin patolojik EEG bulgularını araştırmak ve epilepsi eşiği açısından daha güvenilir olan antipsikotik (AP) ilaçları saptamaktır.

\section{GEREÇ VE YÖNTEM}

Araştırmamız Helsinki Deklarasyonu kararlarına, Hasta Hakları Yönetmeliğine ve etik kurallara uygun olarak, yerel etik kurul olan Zonguldak Karaelmas Üniversitesi (ZKÜ) Uygulama ve Araştırma Hastanesi Etik Kurulu’nun 23.06.2009 tarih ve 2009/08 no'lu toplantı kararında alınan onay sonrası başlanmış ve bir y1l içinde tamamlanmıştır. Hasta ve kontrol grubundaki hastaların yazılı onayları alınmıştır. Araştırmamız ZKÜ Nöroloji Anabilim Dalı Nörofizyoloji Elektroensefalografi (EEG) Laboratuvarı̉nda yapılmıştır.

Bu prospektif vaka kontrol çalışması; Mayıs 2009 ile Mayıs 2010 tarihleri arasında 12 aylık dönem içinde Psikiyatri birimince DSM-IV TR tanı ölçütlerine göre şizofreni veya şizoaffektif bozukluk tanısı konan, en az 2 aydır AP tedavisi değişmeyen hastalara $(n=82)$, şizofreni veya şizoaffektif bozukluğu olup ilaç kullanmayan $(n=20)$ hastalara ve Nöroloji Polikliniğìne baş dönmesi veya baş ağrısı şikayeti ile başvuran nörolojik ve psikiyatrik muayenesi normal, sağlıklı gönüllü $(\mathrm{n}=29)$ kişilere Zonguldak Karaelmas Üniversitesi Uygulama ve Araştırma Hastanesi Nöroloji Anabilim Dalı Nörofizyoloji EEG Laboratuvarı’nda EEG çekilerek yapılmıştır. Çalışmaya; 16 yaşından küçükler; öyküsünde epilepsi, serebral tümör, inme, tamamen iyileşmeyen travmatik beyin hasarı, Down sendromu, migren baş ağrısı, multipl skleroz, HIV pozitiflik, 5 dakikadan uzun süren bilinç kaybı, klinik ve beyin görüntülemesinde fokal beyin lezyonu, deliryum, ilaç yüksek doz kullanımı nedeniyle koma hali olanlar; WAIS IQ'su 70'ten düşük olanlar; ve EEG kaydından 10 gün öncesine kadar ilaç suistimali olan veya ilaç kesilen, 4 ay içinde EKT uygulanmış veya antikonvülsan ilaç kullanımı olan hastalar dahil edilmedi (9).

Çalışmaya alınan tüm hastalara ve kontrol grubuna Nöroloji Anabilim Dalı Nörofizyoloji EEG Laboratuvarı'nda onam formu alındıktan sonra EEG tetkiki yapıldı. EEG kayıtları, Medelec firması tarafından geliştirilen profile mode digital EEG cihazı kullanılarak gerçekleştirildi. EEG çekimleri yarı karanlık 
Tablo 1. EEG skorlaması.

\begin{tabular}{|c|l|}
\hline EEG skorlaması & \\
\hline $\mathbf{0}$ & Normal \\
\hline $\mathbf{1}$ & Diffüz hızlı aktiviteden oluşan zemin ritmi düzensizliği \\
\hline $\mathbf{2}$ & Hafif düzeyde anormallik (yaygın veya frontal simetrik teta dalgalar) \\
\hline $\mathbf{3}$ & $\begin{array}{l}\text { Orta düzeyde anormallik (teta ve delta dalgaları, asimetrik fokal teta veya delta dalgaları, yaygın simetrik teta ve } \\
\text { delta aktiviteli keskin dalga veya faz karşlaştırmalı dalgalar) }\end{array}$ \\
\hline $\mathbf{4}$ & $\begin{array}{l}\text { Ciddi düzeyde anormal (orta düzeydeki anormalliklerle birlikte veya yalnız, diken ve /veya çoklu diken dalga } \\
\text { boşalımları olan aktiviteler, epileptik aktivite olması) }\end{array}$ \\
\hline
\end{tabular}

Tablo 2. Çalışmaya katılan sağlıklı kontrol grubu ile hasta alt gruplarının tanımlayıcı özellikleri

\begin{tabular}{|c|c|c|c|c|c|c|}
\hline & & Kontrol & & Hasta & & \\
\hline Tanımlay & zellik & $\begin{array}{c}\text { Grup } K_{s} \\
n=29\end{array}$ & $\begin{array}{c}\text { Grup }_{\mathbf{H}} \\
\mathbf{n}=20\end{array}$ & $\begin{array}{c}\text { Grup H1 } \\
\mathbf{n}=70\end{array}$ & $\begin{array}{c}\text { Grup H2 } \\
n=12\end{array}$ & p \\
\hline $\begin{array}{l}\text { Yaş (yıl) } \\
\text { ort } \pm \text { ss (m }\end{array}$ & um-maksimum) & $\begin{array}{c}31,3 \pm 12,9 \\
(16-60)\end{array}$ & $\begin{array}{c}31,4 \pm 10,0 \\
(17-52)\end{array}$ & $\begin{array}{c}36,2 \pm 11,7 \\
(17-77)\end{array}$ & $\begin{array}{c}35,0 \pm 8,3 \\
(23-48) \\
\end{array}$ & 0,157 \\
\hline $\begin{array}{l}\text { Hastalık } \\
\text { ort } \pm \text { ss (m }\end{array}$ & $\begin{array}{l}\text { i (ay) } \\
\text { um-maksimum) }\end{array}$ & - & $\begin{array}{c}77,6 \pm 101,8 \\
(0-360)\end{array}$ & $\begin{array}{c}107,0 \pm 90,2 \\
(2-360)\end{array}$ & $\begin{array}{c}129,1 \pm 102 \\
(2-360)\end{array}$ & 0,289 \\
\hline & Erkek n (\%) & $12(\% 41,4)$ & $14(\% 70,0)$ & $40(\% 57,1)$ & $5(\% 41,7)$ & \\
\hline Cinsiyet & Kadın n (\%) & $17(\% 58,6)$ & $6(\% 30,0)$ & $30(\% 42,9)$ & $7(\% 58,3)$ & 0,177 \\
\hline
\end{tabular}

$\mathrm{K}_{\mathrm{S}}$ : Sağlıklı kontrol, $\mathrm{K}_{\mathrm{H}}$ : Hasta kontrol, H1: Atipik antipsikotik, H2: Tipik antipsikotik, SS: standart sapma

bir odada, dinlenme pozisyonunda ve gözler kapalı olarak yapild.

EEG tetkiki; uluslararası EEG ve klinik nörofizyoloji dernekleri tarafından önerilen bir sistem olan Uluslararası 10/20 sistemine göre yerleştirilen 21 yüzeyel gümüş elektrot (Fz, Cz, Pz, A1, A2, Fp1, Fp2, F3, F4, F7, F8, C3, C4, P3, P4, T3, T4, T5, T6, O1, O2) ile referans ve toprak elektrot kullanılarak, 24 kanallı dijital EEG kayıt cihazında (Medelec) uygulandı. Çekim; bipolar ve referans montajlarla ve EKG elektrotları kullanılarak elde edildi (10). Yirmi dakika süren kayıtlar sırasında aktivasyon yöntemleri olan hiperventilasyon (HPV) ve 5, 10, 15 ve $20 \mathrm{~Hz}$ (hertz) frekanslarında intermitan fotik stimülasyon (IFS) uygulandi. $(11,12)$. Tüm EEG’ler ilaç kullanımı bilinmeden kör olarak (Dr. N.F.T) değerlendirildi.

Antipsikotik kullanan olguların EEG kayıtları normal ve patolojik olarak ayrıldı. Hasta alt gruplarının ve kontrollerin EEG değişiklikleri aşağıdaki şekilde gruplandırılarak skorlandı $(1,13,14)$ (bkz. Tablo 1). EEG skoruna normalin bir varyantı olan diffüz hızlı aktiviteden oluşan zemin ritmi düzensizliği de eklendi $(15,16)$. Zemin ritmi, HPV ve IFS' ye duyarlllık ayrıca not edildi.

\section{İstatistiksel Analiz}

İstatistiksel değerlendirme SPSS (Versiyon 13.0) programı kullanılarak yapıldı. Sayısal değişkenlerin normal dağılıma uygunlukları Kolmogorov-Smirnov testi ile incelendi. Sayısal veriler için tanımlayıcı istatistikler ortalama \pm standart sapma, kategorik yapıdaki veriler için sayı ve yüzde olarak ifade edildi. Kategorik yapıdaki değişkenler için gruplar arası farklılıklar ve değişkenler arası ilişkiler ki-kare testi ile incelendi. Sayısal değişkenler için grupların karşılaştırılması tek yönlü varyans analizi (ANOVA) ile yapıldı. EEG skoru ile ilaç dozuna göre ilişkisi için Spearman sıra korelasyon analizi yapıldı. Sonuçlar \%95 güven aralığında değerlendirildi ve $\mathrm{p}<0,05$ değeri anlamlı kabul edildi.

\section{BULGULAR}

Çalışmaya; DSM-IV TR’ye göre şizofreni ve şizoaffektif bozukluk tanısıyla izlenen, yaş ortalaması $34,2 \pm 10,0$ olan, $43(\% 42,1)$ kadın ve $59(\% 57,8)$ erkekten oluşan hastalar grubu [Grup H $(\mathrm{n}=102)]$ ile, yaş ortalaması $31,3 \pm 12,9$ olan, $17(\% 58,6)$ kadın ve $12(\% 41,4)$ erkek sağlıklı gönüllüden oluşan kontrol grubu [Grup $K_{\mathrm{S}}(\mathrm{n}=29)$ ] olmak üzere, toplam 131 kişi dahil edildi ve hepsine EEG çekildi.

Grup H; AAP [klozapin (n:16), ketiapin (n:10), olanzapin (n:14), risperidon (n:20), paliperidon ve aripiprazol gibi diğer AAP (DAAP) (n:10)] kullananlar [Grup H1 ( $\mathrm{n}=70)$ ], TAP (haloperidol ve diğer klasik 
Tablo 3. Klasik ve atipik antipsikotik ilaç kullanımına bağlı EEG bulguları

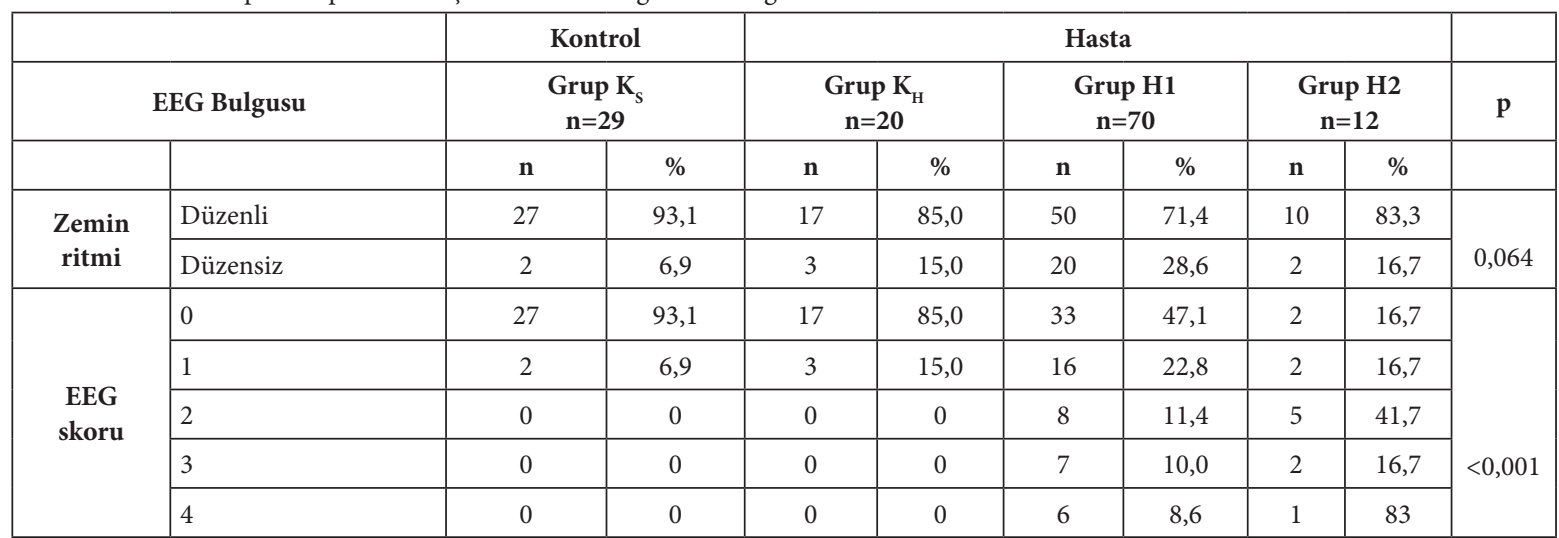

$\mathrm{K}_{\mathrm{S}}$ : Sağlıklı kontrol, $\mathrm{K}_{\mathrm{H}}:$ Hasta kontrol, H1: Atipik antipsikotik, H2: Tipik antipsikotik

AP) kullananlar [Grup H2 (n=12)] ve yeni tanı almış antipsikotik kullanmayan hastalar [Grup $\mathrm{K}_{\mathrm{H}}(\mathrm{n}=20)$ ] olmak üzere üçe ayrıldı.

TAP'ler bir atipik antipsikotik ile kombine edilmişse hasta Grup H2'ye dahil edilmiştir. İlaç grupları tek tek incelenirken de klozapin ile kombine atipik antipsikotik ilaç kullanan hastalar klozapin grubuna dahil edildi.

Kontrol ve hasta gruplarının tanımlayıcı özellikleri Tablo 2'de gösterilmiştir.

Grup H1'de 56 hasta monoterapi (\%80), 14 hasta politerapi (\%20); Grup H2'de 7 hasta monoterapi (\% 58,3), 5 hasta (\%41,7) politerapi alıyordu.

Kullanılan antipsikotik ilaç cinsine göre hastaların dağılımı ve bu dağılıma göre gözlemlenen EEG anormallikleri Tablo 3'de gösterilmiştir. Gruplar arasında istatistiksel anlamlı farklılık bulunmaktadır $(\mathrm{p}<0,001)$. Şöyle ki:

1. EEG'de hafif anormallik sıklığ 1 Grup H1'de Grup H2'ye göre istatistiksel anlamlı düşük ( $\mathrm{p}=0,008)$, Grup $\mathrm{K}_{\mathrm{s}}$ ve Grup $\mathrm{K}_{\mathrm{H}}$ 'ye göre farklı değildir (sırasıyla $\mathrm{p}=0,061$ ve $\mathrm{p}=0,125$ ); Grup H2'de ise hem Grup $\mathrm{K}_{\mathrm{S}}$ hem de $\mathrm{K}_{\mathrm{H}}$ 'ye göre anlamlı yüksekti (sırasıyla $\mathrm{p}=0,0006$ ve $\mathrm{p}=0,003$ ).

2. EEG'de orta derecede anormallik sıklığı Grup H1'de Grup $\mathrm{K}_{\mathrm{s}}, \mathrm{K}_{\mathrm{H}}$ ve $\mathrm{H} 2$ 'den istatistiksel anlamlı farklı değildir ( $\mathrm{p}$ değerleri sırasıyla 0,081, 0,114 ve 0,494), Grup H2'de ise Grup $\mathrm{K}_{\mathrm{S}}$ 'den istatistiksel anlamlı yüksek ( $\mathrm{p}=0,029)$, ancak Grup $\mathrm{K}_{\mathrm{H}}$ 'den istatistiksel farklı değildi $(\mathrm{p}=0,068)$.

3. EEG'de ciddi anormallik yani epileptik aktivite sıklığı hiçbir grup arasında istatistiksel anlamlı farklı değildi.
4. EEG'de zemin ritminin diffüz hızlı olma sıklığı hiçbir grup arasında istatistiksel anlamlı farklı değildi.

5. EEG’nin normal olma sıkl $\breve{g ̆ g}_{1}$ Grup H1'de, Grup $\mathrm{K}_{\mathrm{s}}$ ve $\mathrm{K}_{\mathrm{H}}$ 'ye göre istatistiksel anlamlı düşük (sırasıyla $\mathrm{p}=0,0001$ ve $\mathrm{p}=0,003)$, Grup H2'ye göre istatistiksel anlamlı yüksekti $(\mathrm{p}=0,05)$. Grup H2'de de Grup $\mathrm{K}_{\mathrm{S}}$ ve Grup $\mathrm{K}_{\mathrm{H}}$ 'ye göre istatistiksel anlamlı düşüktü (sirasiyla $\mathrm{p}=0,0001$ ve $\mathrm{p}=0,0006$ ).

6. Grup $\mathrm{K}_{\mathrm{S}}$ ve Grup $\mathrm{K}_{\mathrm{H}}$ arasında EEG skorlarının tamamı açısından istatistiksel açıdan anlamlı bir fark bulunmamaktaydı.

EEG skorlarına göre atipik antipsikotik ilaçların EEG'ye etkileri Tablo 4'te gösterilmiştir. Tablo 4'te gösterilen EEG skorlama gruplarının bazı kategorileri birleştirilerek normal (EEG skoru 0 ve 1 olanlar), epileptik aktivite dişı anormallik (EEG skoru 2 ve 3 olanlar) ve epileptik aktivite (EEG skoru 4 olanlar) olarak tekrar oluşturuldu (Tablo 5). Buna göre kullanılan antipsikotik ilaçların EEG’ye etkileri incelendiğinde (Tablo 5) epileptik aktivite toplam yedi hastada [klozapin ( $\mathrm{n}=5)$, ketiapin ( $\mathrm{n}=1$ ) ve Grup H2'de $(\mathrm{n}=1)$ ] saptand. Grup $\mathrm{K}_{\mathrm{S}}$ ve Grup $\mathrm{K}_{\mathrm{H}}$ 'deki hastaların tamamının EEG skoru normal bulundu. Klozapin kullanan grupta epileptik aktivite oluşturma riski Grup $\mathrm{K}_{\mathrm{S}}$ ve $\mathrm{K}_{\mathrm{H}}$ 'ye göre istatistiksel anlamlı yüksek bulundu ( $\mathrm{p}$ değerleri sirasıyla 0,002 ve 0,011 ). Ketiapin kullanan hastaların $\% 10$ 'unda, TAP kullananların da \%8,3'ünde epileptik aktivite gözlendi (Grup $\mathrm{K}_{\mathrm{S}}$ ve $\mathrm{K}_{\mathrm{H}}$ 'ye göre $\mathrm{p}$ değerleri s1rasıyla ketiapin için 0,092 ve 0,161 , TAP için 0,124 ve $0,199)$, ayrıca istatistiksel anlamlı olmasa da epileptik aktivite oluşturma riskleri klozapine göre düşük bulundu. Epileptik aktivite dışı EEG anormallikleri Grup 
Tablo 4. Tipik ve atipik antipsikotik ilaç kullananların EEG skoruna göre dağılımı

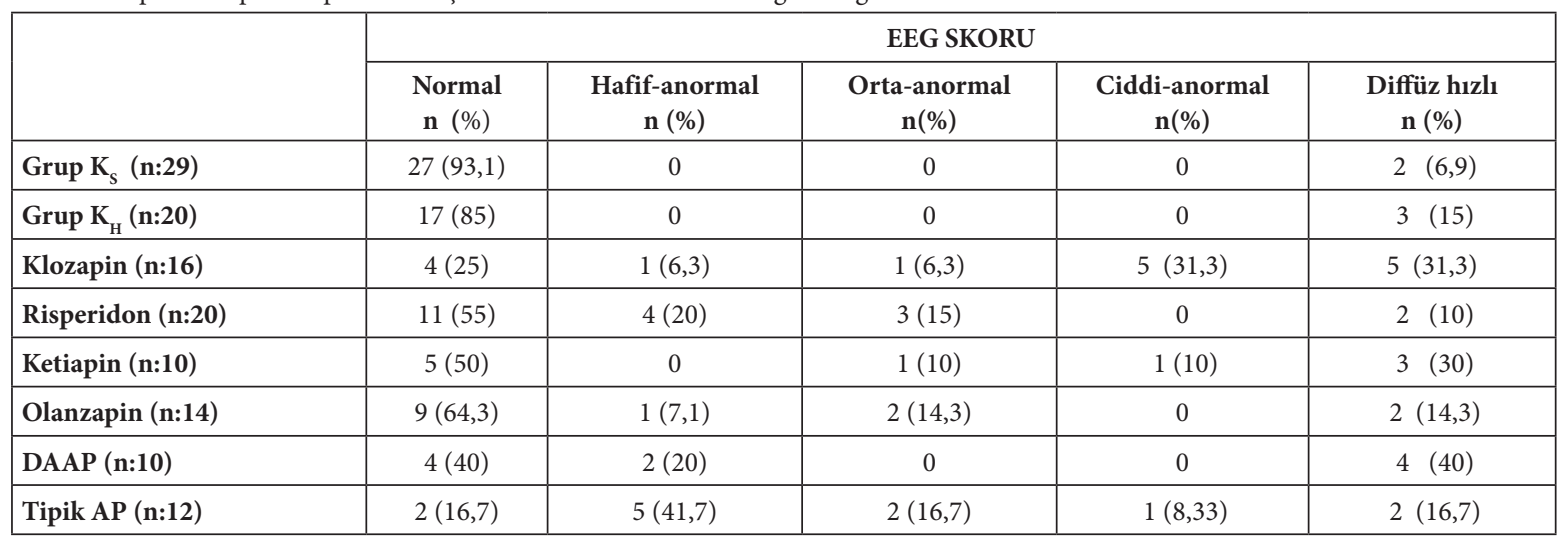

$\mathrm{K}_{\mathrm{S}}$ : Sağlıklı kontrol, $\mathrm{K}_{\mathrm{H}}$ : Hasta kontrol, DAAP: Diğer Atipik antipsikotik, AP: Antipsikotik

Tablo 5. Tipik ve atipik antipsikotik ilaç kullananların EEG bulguları

\begin{tabular}{|c|c|c|c|}
\hline \multirow{2}{*}{} & \multicolumn{3}{|c|}{ EEG BULGULARI } \\
\cline { 2 - 4 } & Normal n (\%) & EA dişı anormallik n (\%) & EA n (\%) \\
\hline Grup K $_{\mathrm{S}}$ & $29(\% 100)$ & 0 & 0 \\
\hline Grup K & $20(\% 100)$ & $2(\% 12,5)$ & $5(\% 31,3)$ \\
\hline Klozapin & $9(\% 36,3)$ & $7(\% 35)$ & 0 \\
\hline Risperidon & $13(\% 65)$ & $1(\% 10)$ & 0 \\
\hline Ketiapin & $8(\% 80)$ & $3(\% 21,4)$ & 0 \\
\hline Olanzapin & $11(\% 78,6)$ & $2(\% 20)$ & $1(\% 8,33)$ \\
\hline DAAP & $8(\% 80)$ & $7(\% 58,3)$ & 0 \\
\hline Tipik AP & $4(\% 33,3)$ & & \\
\hline
\end{tabular}

$\mathrm{K}_{\mathrm{S}}$ : Sağlıklı kontrol, $\mathrm{K}_{\mathrm{H}}$ : Hasta kontrol, DAAP: Diğer atipik antipsikotik, AP: Antipsikotik, EA: Epileptik aktivite

$\mathrm{K}_{\mathrm{S}}$ ve Grup $\mathrm{K}_{\mathrm{H}}$ 'ye göre sirasiyla Grup H2'de (sirasiyla $\mathrm{p}=0,0001$ ve $\mathrm{p}=0,0006$ ), risperidon kullananlarda (s1rasiyla $\mathrm{p}=0,001$ ve $\mathrm{p}=0,006$ ), olanzapin kullananlarda (sirasiyla $\mathrm{p}=0,013$ ve $\mathrm{p}=0,039$ ) ve DAAP kullananlarda (sirasiyla $\mathrm{p}=0,018$ ve $\mathrm{p}=0,047$ ) istatistiksel anlaml yüksekti; klozapin kullananlarda Grup $\mathrm{K}_{\mathrm{s}}$ 'ye göre anlamlı yüksek ( $\mathrm{p}=0,05)$, ancak grup $\mathrm{K}_{\mathrm{H}}$ 'den farklı değildi $(\mathrm{p}=0,113)$; ketiapin kullananlarda ise gruplar arasinda anlamlı fark yoktu. Normal EEG bulgularıyla en fazla ketiapin ve DAAP kullanımı sırasında, en az da tipik antipsikotiklerin kullanımı sırasında karşılaşıldı ( $\mathrm{p}=0,012)$ Ketiapin veya DAAP kullananlarda EEG’nin normal saptanması kontrol gruplarından farklı değildi $(\mathrm{p}=0,114)$ (Tablo 5)

EEG skorları ile ilaç dozları arasında ise istatistiksel anlamlı bir ilişki gözlenmedi.

\section{TARTIŞMA}

Bu çalışmamızda epileptik aktivitenin istatistiksel anlamlı olacak şekilde klozapin kullanımıyla ortaya çıktığı, bunu istatistiksel olarak anlamsız olmakla birlikte ketiapin ve TAP'lerin izlediği, epileptik aktivite dışı EEG anormalliklerinin ise en fazla TAP kullanımında olduğu bunu risperidon, olanzapin, DAAP ve klozapinin izlediği bulundu. EEG'nin en fazla DAAP kullanımında normal kaldığı saptandı.

AP ilaçların bünyesindeki farmakodinamik farkl1lıklar, beynin elektriksel aktiviteleri üzerinde değişik etkilere yol açmaktadır $(13,17,18)$. Bunların altında yatan mekanizma, AAP ilaçların dopaminerjik sistem dışındaki diğer sistemler üzerindeki etkileri olabilir. Şöyle ki; D2 reseptör blokajı ve 5 HT2A reseptör blokajı yapan AAP ilaçlar bu sistemler üzerinden diğer sistemleri de $(19,20)$ etkilemektedir: 
1. D2 reseptörlerinin aşırı uyarımı glutamaterjik NMDA reseptörü üzerinde inhibisyon yapabilirken, bunun tersine NMDA reseptör inhibisyonu da, D2 reseptörlerinin aşırı uyarımı ile ilgili olabilmektedir $(21,22)$. Nitekim AP'lerin akut ve kronik tatbikinin psikozda azalmış NMDA reseptör etkinliğini hücresel ve davranışsal düzeyde, seçici ve deneysel olarak artırdığı da gösterilmiştir $(1,23)$.

2. AAP'ler 5HT2A reseptörleri üzerinden serotonerjik seviyede artma yapan ajanlardir $(21,22)$. 5HT2A reseptörleri beyinde yaygındır ve en yüksek konsantrasyonda kortekste bulunmaktadır. Kortikal ve hipokampal piramidal glutamaterjik nöronlarda ve GABAerjik ara nöronlarda da bulunurlar. GABAerjik ara nöronlardaki etkileriyle GABA salınımını arttırabildikleri gibi, piramidal nöronlardaki etkileriyle $\mathrm{GABA}^{\mathrm{A}}$ akımının etkisini de azaltabilirler $(23,24)$.

Deneysel ortamda klozapin, NMDA reseptör antagonistleri ile oluşturulan etkileri en güçlü bloke eden AAP'dir. Bu açıdan bakıldığında klozapinin, NMDA reseptör etkinliğini artırarak EEG'de anormallik yaptığı ve epileptik aktivite oluşturduğu da söylenebilir (25). Klozapin tedavisi sonucunda gelişen nöbetlerin, özellikle klozapinin asetilkolin-M reseptörlerine olan afinitesine bağlı olduğu da düşünülmektedir $(6,7)$. Üç yüz yirmi üç psikiyatrik hastayla yapılan bir EEG çalışmasında, AAP ajanlar içerisinde klozapinin EEG anormalliği riski en yüksek bulunmuştur (1). Başka çalışmalarda da klozapin tedavisi almakta olan hastaların en azından üçte birinde veya daha fazlasında EEG anormalliği saptanmıştır (6,7,26-30). Bu çalışmamızda da antipsikotikler arasında en fazla klozapinin EEG’de epileptik aktivite oluşturduğu gözlenmiştir.

Ayrıca epileptik nöbetlerin varlığı ve daha nadir olarak status epileptikus neredeyse bütün TAP ilaçlar için tanımlanmıştır $(1,14,17)$. TAP ve AAP ile yapılan farklı çalışmalarda epileptiform anomalilerin yanı sıra, EEG'de zemin aktivitesinde yaygın yavaşlama, yavaş dalga aktivitesi, alfa ritminde artış bildirilmiştir $(2,3)$. Wetzel ve arkadaşlarının yaptığı çalışmada AAP ilaç kullanımı sonrasinda delta ve/veya teta frekans bantlarının amplitütlerindeki artışa ilişkin anlamlı bir farklılık ortaya çıktığı görülmüştür (31). Bu çalışmada da sirasiyla en fazladan aza doğru TAP, risperidon, olanzapin ve DAAP kullananlarda EEG'de istatistiksel an- lamlı epileptik aktivite dışı anormallikler gözlenmiştir. EEG'yi en az DAAP kullanımının bozduğu, istatistiksel anlamlı veya anlamsız hiçbir epileptik aktivite yapmadığı bulunmuştur.

Olanzapinin EEG'de yavaşlamayı klozapine göre daha düşük oranda indüklediğini gösteren farklı çalışmalar bulunmaktadır. (23,32). Ayrica 1997'de Beasley ve arkadaşları, 1999'da ise Wyderski ve arkadaşlarının yaptığ 1 araştırmalarda D1-4, 5HT2, H1, Ach-M reseptörlerini bloke eden "olanzapin" ile bildirilen EEG'lerdeki nöbet oranları rutin çekilen EEG'lerden yüksek bulunmuştur $(33,34)$. Çalışmaların bir kısmında da AAP’lerin klasik antipsikotikler ile karşılaştırıldığında yan etkilerinin daha düşük olduğu ve hastalarda yaşam kalitesinin daha yüksek olduğu gösterilmiştir (35). Bu çalışmada da epileptik aktivite dışı EEG anormalliğinin en az olduğu ilaç grubu ketiapin, DAAP ve olanzapindir. Olanzapinin klozapine göre epileptik aktivite yapmamış olmasının nedeni etkiledikleri reseptörlerin benzer olmasına rağmen 5HT-1A ile 5HT-7'ye etkisiz olmalarından kaynaklanıyor olabilir (31,35-38).

Sonuçta bu çalışmada elde edilen bulgular ışığında TAP veya AAP kullanan kişilerde EEG anormalliği ortaya çıabilmektedir. Özellikle AAP'lerden klozapin kullanımı ile ek olarak epileptik aktivite gözlendiği bilindiğinden, bu ilaçları kullanan hastaların EEG ile takip edilmesi, epilepsisi olan psikotik hastalarda antipsikotik ilaç tedavisine başlanırken EEG'yi en az bozan ve epileptik aktivite yapmayan DAAP'ler tercih edilmesi önerilebilir.

\section{KAYNAKLAR}

1. Centorrino F, Price BH, Tuttle M, Bahk WM, Hennen J, Albert MJ, et al. EEG abnormalities during treatment with typical and atypical antipsychotics. Am J Psychiatry. 2002;159(1):109-15.

2. Roubicek J, Major I. EEG profile and behavioral changes after a single dose of clozapine in normals and schizophrenics. Biol Psychiatry. 1977;12(5):613-33.

3. Moore NC, Tucker KA, Brin FB, Merai P, Shillcut SD, Coburn KL. Positive symptoms of schizophrenia: Response to haloperidol and remoxipride is associated with increased alpha EEG activity. Hum Psychopharmacol. 1999;12(1):75-80.

4. Stevens JR, Bigelow L, Denney D, Lipkin J, Livermore $\mathrm{AH}$, Rauscher F, et al. Telemetered EEG-EOG during psychotic behaviors of schizophrenia. Arch Gen Psychi- 
atry. 1979;36(3):251-62.

5. Bridgers SL. Epileptiform abnormalities discovered on electroencephalographic screening of psychiatric inpatients. Arch Neurol. 1987;44(3):312-6.

6. Silvestri RC, Bromfield EB, Khoshbin S. Clozapine-induced seizures and EEG abnormalities in ambulatory psychiatric patients. Ann Pharmacother. 1998;32(11):1147-51.

7. Devinsky O, Honigfeld G, Patin J. Clozapine-related seizures. Neurology 1991;41(3):369-71.

8. Baldessarini RJ. Drugs and the treatment of psychiatric disorders: depression and anxiety disorders. In: Hardman JG, Limbird LE, Gilman AG (ed.), Goodman and Gilman's The Pharmacological Basis of Therapeutics, 10. ed. New York: McGraw-Hill; 2001:447-83.

9. Amerikan Psikiyatri Birliği. Psikiyatride Hastalıkların Tanımlanması ve Sınıflandırılması El Kitabı, 4. ed. (DSM-IV TR), (çev. Ertuğrul Köroğlu). Ankara: Hekimler Yayın Birliği; 2001:137-42.

10. American Electroencephalographic Society. Guideline seven: a proposal for standard montages to be used in clinical EEG. J Clin neurophsiol. 1994;11(1):30-6.

11. Small JG. Psychiatric disorders and EEG. In: Niedermeyer E, DaSilva FL (ed.), Electroencephalography: Basic Principles, Clinical Applications, and Related Fields, 5. ed. Baltimore: Lippincott Williams \& Wilkins; 1999:639-61.

12. Aminoff MJ. Electroencephalography: general principles and clinical applications. In: Aminoff MJ (ed.), Electrodiagnosis in Clinical Neurology, 3. ed. New York: Churchill-Livingstone; 1992:41-91.

13. Saletu B, Anderer P, Kinsperger K, Grünberger J. Topographic brain mapping of EEG in neuropsychopharmacology. Part II: Clinical applications (pharmaco EEG imaging). Methods Find Exp Clin Pharmacol.1987;9(6):385-408.

14. Westphal KP, Grozinger B, Diekmann V, Scherb W, Reess J, Leibing U, et al. Slower theta activity over the midfrontal cortex in schizophrenic patients. Acta Psychiatr Scand. 1990;81(2):132-8.

15. Jirsch JD, Urrestarazu E, LeVan P, Olivier A, Dubeau F, Gotman J. High-frequency oscillations during human focal seizures. Brain. 2006;129(6):1593-608.

16. Staba RJ, Wilson CL, Bragin A, Fried I, Engel J Jr. Quantitative analysis of high-frequency oscillations (80-500 $\mathrm{Hz})$ recorded in human epileptic hippocampus and entorhinal cortex. J Neurophysiol. 2002;88(4):1743-52.

17. Yağcıŏlu EA. Antipsikotik ilaçların etki mekanizmaları: şizofreni tedavisinde "atipiklik" bir üstünlük mü? Türk Psikiyatri Derg. 2007;18(4):364-74.

18. Amann BL, Pogarell O, Mergl R, Juckel G, Grunze H, Mulert C, et al. EEG abnormalities associated with antipsychotics: a comparison of quetiapine, olanzapine, ha- loperidol and healthy subjects. Hum Psychopharmacol. 2003;18(8):641-6.

19. Miller AL, Hall CS, Buchanan RW, Buckley PF, Chiles JA, Conley RR, et al. The Texas Medication Algorithm Project antipsychotic algorithm for schizophrenia: 2003 update. J Clin Psychiatry. 2004;65(4):500-8.

20. Farah A. Atypicality of atypical antipsychotics. Prim Care Companion J Clin Psychiatry. 2005;7(6):268-74.

21. Davis KL, Kahn RS, Ko G, Davidson M. Dopamine in schizophrenia: a review and reconceptualization. Am J Psychiatry. 1991;148(11):1474-86.

22. Herz MI, Marder SR. Schizophrenia: Comprehensive Treatment and Management. Philadelphia: Lippincott Williams \& Wilkins; 2002:9-21.

23. Conley RR, Meltzer HY. Adverse events related to olanzapine. J Clin Psychiatry. 2000;61(Suppl 8):26-9.

24. Kramer M, Simpson G, Maciulis V, Kushner S, Vijapurkar U, Lim P, et al. Paliperidone extended-release tablets for prevention of symptom recurrence in patients with schizophrenia: a randomized, double-blind, placebocontrolled study. J Clin Psychopharmacol. 2007;27(1):614.

25. Olney JW, Farber NB Efficacy of clozapine compared with other antipsychotics in preventing NMDA-antagonist neurotoxicity. J Clin Psychiatry. 1994;55(Suppl B):43-6.

26. Welch J, Manschreck T, Redmond D. Clozapine-induced seizures and EEG changes. J Neuropsychiatry Clin Neurosci. 1994;6(3):250-6.

27. Ichikawa J, Dai J, O’Laughlin IA. Atypical, but not typical, antipsychotic drugs increase cortical acetylcholine release without an effect in the nucleus accumbens or striatum. Neuropsychopharmacology 2002;26(3):32539.

28. Risby ED, Epstein CM, Jewart RD, Nguyen BV, Morgan WN, Risch SC, et al. Clozapine-induced EEG abnormalities and clinical response to clozapine. J Neuropsychiatry Clin Neurosci. 1995;7(4):466-70.

29. Freudenreich O, Weiner RD, McEvoy JP. Clozapine-induced electroencephalogram changes as a function of clozapine serum levels. Biol Psychiatry. 1997;42(2):13237.

30. Baldessarini RJ, Frankenburg FR. Clozapine: a novel antipsychotic agent. N Engl J Med. 1991;324(11):746-54.

31. Wetzel H, Szegedi A, Hain C, Wiesner J, Schlegel S, Benkert O. Seroquel (ICI 204 636), a putative "atypical" antipsychotic, in schizophrenia with positive symptomatology: results of an open clinical trial and changes of neuroendocrinological and EEG parameters. Psychopharmacology (Berl) 1995;119(2):231-8.

32. Chengappa KN, Pollock BG, Parepally H, Levine J, Kirshner MA, Brar JS, et al. Anticholinergic differences among patients receiving standard clinical doses of olanzapine or clozapine. J Clin Psychopharmacol. 
2000;20(3):311-6.

33. Beasley CM Jr, Tollefson GD, Tran PV. Safety of olanzapine. J Clin Psychiatry. 1997;58(Suppl 10):13-7.

34. Wyderski RJ, Starrett WG, Abou-Saif A. Fatal status epilepticus associated with olanzapine therapy. Ann Pharmacother. 1999;33(7-8):787-9.

35. Stahll SM. Stahl's Essential Psychopharmacology: Neuroscientific Basis and Practical Application, 3. ed. New York: Cambridge University Press; 2008:401-50.
36. Jufe G. Psicofarmacología Práctica. Buenos Aires: Editorial Polemos; 2001:129-40.

37. Bezchlibnyk-Butler KZ, Jeffries JJ. Clinical handbook of psychotropic drugs,13. ed. Toronto: Hogrefe \& Huber Publishers; 2003:100-29.

38. Strange PG. Antipsychotic drugs: importance of dopamine receptors for mechanisms of therapeutic actions and side effects. Pharmacol Rev. 2001;53(1):119-33. 